\title{
Perceived risk factors for severe Covid-19 symptoms and their association with health behaviours: Findings from the HEBECO study ${ }^{\text {in }}$
}

\author{
Aleksandra Herbec ${ }^{\text {a,b,c, ", Jamie Brown }}{ }^{\text {a }}$, Sarah E. Jackson ${ }^{\text {a }}$, Dimitra Kale ${ }^{\text {a }}$, \\ Mateusz Zatoński ${ }^{\mathrm{d}, \mathrm{e}}$, Claire Garnett ${ }^{\mathrm{a}}$, Tim Chadborn ${ }^{\mathrm{c}}$, Lion Shahab ${ }^{\mathrm{a}}$

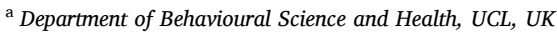 \\ ${ }^{\mathrm{b}}$ Department of Clinical, Educational and Health Psychology, UCL, UK \\ ${ }^{\mathrm{c}}$ Behavioural Insights, Public Health England, UK \\ ${ }^{\mathrm{d}}$ Institute - European Observatory of Health Inequalities, Calisia University, Kalisz, Poland \\ e Tobacco Control Research Group, Department for Health, University of Bath, UK
}

\section{A R T I C L E I N F O}

\section{PsycINFO classification:}

3300

3360

Keywords:

Covid-19

Risk perceptions

Health behaviours

Cross-sectional

Optimism bias

\begin{abstract}
A B S T R A C T
Risk perceptions are important influences on health behaviours. We used descriptive statistics and multivariable logistic regression models to assess cross-sectionally risk perceptions for severe Covid-19 symptoms and their health behaviour correlates among 2206 UK adults from the HEBECO study. The great majority (89-99\%) classified age $70+$, having comorbidities, being a key worker, overweight, and from an ethnic minority as increasing the risk. People were less sure about alcohol drinking, vaping, and nicotine replacement therapy use (17.4-29.5\% responding 'don't know'). Relative to those who did not, those who engaged in the following behaviours had higher odds of classifying these behaviours as (i) decreasing the risk: smoking cigarettes (adjusted odds ratios, aORs, 95\% CI = 2.26, 1.39-3.37), and using e-cigarettes (aORs = 5.80, 3.25-10.34); (ii) having no impact: smoking cigarettes $(1.98 ; 1.42-2.76)$, using e-cigarettes (aORs $=2.63,1.96-3.50)$, drinking alcohol (aORs $=1.75,1.31-2.33$ ); and lower odds of classifying these as increasing the risk: smoking cigarettes (aORs: $0.43,0.32-0.56$ ), using e-cigarettes (aORs $=0.25,0.18-0.35$ ). Similarly, eating more fruit and vegetables was associated with classifying unhealthy diet as 'increasing risk' ( $\mathrm{aOR}=1.37,1.12-1.69$ ), and exercising more with classifying regular physical activity as 'decreasing risk' ( $\mathrm{aOR}=2.42,1.75-3.34$ ). Risk perceptions for severe Covid-19 among UK adults were lower for their own health behaviours, evidencing optimism bias. These risk perceptions may form barriers to changing people's own unhealthy behaviours, make them less responsive to interventions that refer to the risk of Covid-19 as a motivating factor, and exacerbate inequalities in health behaviours and outcomes.
\end{abstract}

\section{Introduction}

As of November 2021, the Covid-19 pandemic has resulted in over 5 million deaths worldwide and over 250 million confirmed infections caused by the SARS-CoV-2 virus (WHO, 2020). Research on risk and protective factors for severe Covid-19 outcomes continues to develop, which could help to lower hospitalisations and mortality. Furthermore, the Covid-19 pandemic could be a teachable moment and a catalyst for a number of positive lifestyle changes with long-term health benefits (Brust et al., 2021). For example, in the UK a new campaign Better Health was launched in the summer of 2021 to align with the increased understanding of the role of obesity in Covid-19 severe outcomes (Public Health England, 2021). Notwithstanding the importance of context, resources and social opportunities (Michie et al., 2011), risk perceptions can be important influences on health behaviours and behaviour change. At the same time, inaccurate beliefs or cognitive biases can lead to missed opportunities or misguided behaviours that could pose further risk and contribute to health inequalities (Branstrom et al., 2006; Brewer et al., 2007; Ferrer \& Klein, 2015; Michie et al., 2011; Shahab et al., 2018). Understanding the beliefs that adults hold regarding risk factors for severe Covid-19 symptoms and their correlates can contribute to the design or implementation of relevant behaviour change campaigns and

\footnotetext{
4 Protocol pre-registration: https://osf.io/392sp DOI: 10.17605/OSF.IO/392SP.

* Corresponding author at: Department of Clinical, Educational and Health Psychology, UCL, 1-19 Torrington Place, London WC1E 7HB, UK.

E-mail address: a.herbec@ucl.ac.uk (A. Herbec).
} 
interventions during the current and future pandemics or other health crises.

Risk perceptions are on a pathway to behaviour or behaviour change in many models of health behaviours, including the Extended Parallel Process Model (EPPM (Witte, 1992)), Protection Motivation Theory (PMT) (Rogers \& Protection, 1975) and the Capability, Motivation and Opportunity-Behaviour Model (COM-B Model (Michie et al., 2011)). These theories and models posit that perceiving certain factors or behaviours as risky to oneself can increase motivation to engage in relevant protective behaviours, particularly if the context or one's skills are also favourable to such a positive change. Risk perception was demonstrated to be important for a range of health behaviours, including taking part in vaccinations (Brewer et al., 2007), cancer screening (Katapodi et al., 2004) and engaging in health protective behaviours during the Covid-19 pandemic (Wise et al., 2020). For the Covid-19 pandemic to successfully act as a teachable moment, perceiving one's own unhealthy behaviours as increasing the risk of severe Covid-19 symptoms could be an important facilitator of positive lifestyle changes.

However, a number of cognitive biases can counter or lower the perceived risk and thus undermine the motivation to engage in healthprotective behaviours. These biases include optimism bias (overestimating and underestimating chances of experiencing favourable and unfavourable events, respectively (Weinstein, 1980)), illusory control (Presson \& Benassi, 1996), cognitive consistency (Gawronski, 2012) and confirmation bias (Nickerson, 1998). For example, unrealistic optimism bias was found among smokers who were underestimating the health risk of smoking, which was associated with lower quit rates and motivation to quit (Dillard et al., 2006). Similar findings were observed for alcohol drinking (Masiero et al., 2018), engaging in risky sexual behaviours (Chapin, 2010), and opioid use (Wilder et al., 2016). Presence of biases such as optimism bias could negatively impact on the positive lifestyle changes during the Covid-19 pandemic.

To date many studies have researched risk perceptions and protective behaviours (e.g. use of face coverings, hand washing, taking vaccinations) during the Covid-19 pandemic, and their correlates and predictors (e.g. Abdelrahman, 2020; Dryhurst et al., 2020; Siegrist et al., 2021; Wise et al., 2020). In general, these studies found that risk perceptions (e.g. perceptions of being at risk of Covid-19 infection) were associated or predictive of the adoption of different protective behaviours, suggesting that interventions aimed at increasing risk perceptions could promote engagement in the desired protective behaviours. The present study makes a contribution to the literature on Covid-19 by investigating risk perceptions regarding other factors and health behaviours that could impact on the severity of Covid-19 infections, with these perceptions in turn having a potential to shape other health behaviours during future pandemics.

Specifically, in addition to the protective behaviours (e.g. hand washing), a number of other conditions, characteristics and health behaviours have been implied as potentially associated with the severity of Covid-19 infections. These factors include older age, higher body mass index, medical comorbidities, ethnic minority background, male sex, socioeconomic disadvantage, and occupation (e.g. healthcare professional) (Aveyard et al., 2020; CDC, 2020; Ioannou et al., 2020; NHS, 2020; The OpenSAFELY Collaborative et al., 2020; Ward et al., 2020). Additionally, certain health behaviours have also been suggested to impact on Covid-19 infections and outcomes, such as unhealthy diet (Butler \& Barrientos, 2020), low physical activity (Sallis et al., 2020), and not exposing skin to the sun leading to vitamin D deficiency (Grant et al., 2020; Rhodes et al., 2020). Smoking history was also shown to be associated with Covid-19 outcomes, but the findings remain uncertain regarding the direction of effect, with some studies pointing to a protective effect of nicotine use (Farsalinos et al., 2020a; Farsalinos et al., 2020b; Hartmann-Boyce \& Lindson, 2020; Simons et al., 2020). However, research on the Covid-19 risk factors has suffered from important limitations including small sample sizes, reliance on observational and poorly controlled data, and incomplete data on health behaviours, which has contributed to scientific uncertainty (Simons et al., 2020; The OpenSAFELY Collaborative et al., 2020).

Beliefs regarding whether health behaviours are risky or protective of Covid-19 have already shaped some of the health behaviours during the pandemic. For example, a minority of current smokers and e-cigarette users reported attempting to quit smoking or vaping, respectively, due to Covid-19 (ASH, 2020; Tattan-Birch et al., 2020). Meanwhile, in France early reports that nicotine may be protective against Covid-19 (Changeux et al., 2020; Miyara et al., 2020) led to a rapid increase in purchasing of nicotine replacement therapy (NRT) (Dalton, 2020). In Iran, cases of alcohol poisoning were registered following unfounded suggestions that alcohol could kill the SARS-CoV-2 virus (Aghababaeian et al., 2020; Shokoohi et al., 2020).

Understanding adults' risk perceptions for severe Covid-19 symptoms and their correlates could contribute to the design and implementation of health promotion programmes during the current pandemic or other health crises. The present study uses data from the HEalth BEhaviours during the Covid-19 pandemic (HEBECO) study for project details and the survey wording see https://osf.io/392sp to answer three research questions:

1. Between June and August 2020, to what extent did UK adults consider the following factors as (i) increasing risk, (ii) decreasing risk, or (iii) having no impact on more severe Covid-19 symptoms: older age, medical comorbidities, ethnic minority, being a key worker, vitamin D deficiency, and poor housing and lower income as proxies for poor living conditions, smoking, e-cigarette use, NRT use, alcohol use, physical activity, unhealthy diet, spending time in the sun?

2. To what extent did perceptions about health behaviours (tobacco smoking, e-cigarette use, alcohol drinking, physical activity, eating fruit and veg) as risk factors for severe Covid-19 symptoms differ according to participants' own engagement in these behaviours?

3. What other factors were perceived as increasing the risk for Covid-19 among adults?

\section{Materials and methods}

\subsection{Design}

This was a cross-sectional study with the data drawn from the longitudinal HEBECO study (https://www.ucl-covid19research.co.uk/). The outcome and the majority of explanatory variables were collected at the 1-month follow-up of the HEBECO study (collected between 6th June 2020 and 26th August). A small number of socio-demographic measures were collected only during the HEBECO baseline to limit participant burden (collected between 23rd April 2020 till 25th July), which were considered as time-invariant for the purpose of the analysis (e.g. ethnicity, gender, education level). The study was designed after the data were collected, but the data analysis protocol was pre-specified and pre-registered on Open Science Framework (OSF, https://osf. io/392sp) before the data were inspected. For HEBECO study details and the survey wording see https://osf.io/sbgru/.

\subsection{Sample}

The HEBECO survey was conducted among a convenience sample of UK-based adults. The recruitment campaign into the baseline involved sharing study invitations via multiple channels, including unpaid and paid advertisements on social media (e.g. Facebook, Twitter, Reddit), email campaign across the networks of UCL, other universities, Public Health England, Cancer Research UK, charities and local authorities across the UK. The present study used data from participants who were (a) recruited into the HEBECO study and (b) who were successfully followed-up at 1 month and answered questions on risk perceptions that were added to the 1-month follow-up survey. 


\subsection{Measures}

\subsubsection{Outcome measures assessed at 1-month follow-up}

Risk perceptions of individual factors for severe Covid-19 symptoms were assessed by one question: "How do you think the following may affect, or not, the risk of having more severe symptoms of Covid-19?" The answer options for each listed potential risk factor were: lowers risk, no impact, increases risk, and don't know. The list of factors were drawn from among those that were researched or reported in the media as factors related to Covid-19 outcomes at the time of data collection: being 70 years old and older, being from an ethnic minority, existing medical conditions, being overweight (Aveyard et al., 2020; CDC, 2020; Ioannou et al., 2020; NHS, 2020; The OpenSAFELY Collaborative et al., 2020; Ward et al., 2020), regular physical activity (Sallis et al., 2020), eating unhealthy foods (Butler \& Barrientos, 2020), smoking cigarettes, using e-cigarettes (vaping), using nicotine replacement therapy (e.g. nicotine gum, patch) (ASH, 2020; Tattan-Birch et al., 2020), vitamin D deficiency, spending time in the sun (Grant et al., 2020; Rhodes et al., 2020), drinking alcohol (Aghababaeian et al., 2020; Shokoohi et al., 2020), lower income, poor housing, being a key worker (Aveyard et al., 2020; CDC, 2020; Ioannou et al., 2020; NHS, 2020; The OpenSAFELY Collaborative et al., 2020; Ward et al., 2020).

\subsubsection{Correlates and confounding variables - health behaviours assessed at 1 month follow-up}

We used validated or previously published measures, where possible, and assessed clinically-meaningful criteria to assess health behaviours at 1-month follow-up. Based on these measures we derived the following: (1) current cigarette and other tobacco smoking (yes/no; Fidler et al., 2011); (2) current e-cigarette use (yes/no, adapted from Fidler et al., 2011); (3) meeting the World Health Organisation recommendations for physical activity (meeting no recommendations; vs meeting the recommended levels of either muscle strength training ( $\geq 2$ days/week) or moderate-to-vigorous aerobic training ( $\geq 150 \mathrm{~min} /$ week); vs meeting recommendations for both types of physical activity; Bennie et al., 2019); (4) fruit and vegetable consumption (a few times per day/less often; (Critchlow et al., 2020)); and (5) weekly alcohol consumption ( 0 units in the past week; vs low risk drinking $\leq 14$ units/week; vs high risk drinking >14 units per week; UK Government, 2016 (UK Department of Health, 2016); using questions from Audit-C (Bradley et al., 2007)). Questions about physical activity and alcohol consumption were supplemented by visuals to aid interpretation.

\subsubsection{Correlates and confounders - socio-demographic and health characteristics}

Measures marked with * were assessed using items used in the Smoking and Alcohol Toolkit study (Fidler et al., 2011). The derived correlates assessed at baseline: age* $(<35,36-69,70+$; these age cutoffs were selected to divide adults into low, moderate, and high risk groups, in line with the messaging about the pandemic and shielding of those aged 70+); gender* (female vs all other); ethnicity* (white ethnicity vs all other); education* (post-16 education or higher vs not); any health condition (yes/no); body mass index, BMI ( $\leq 24.9,25-29.9$, $\geq 30 \mathrm{~kg} / \mathrm{m}^{2}$, unknown); living with vulnerable persons (yes/no); working as a key worker (yes/no); pre-Covid-19 annual household income (high, $\geq 50,000 \mathrm{GBP}$, vs medium-low, $<50,000 \mathrm{GBP}$, vs prefer not to say); housing tenure* (mortgage or own outright/other). Correlates assessed at 1-month follow-up were: employment* (yes/no), perceived risk of Covid-19 to one's health (no or minor risk/other). Finally, the analyses were adjusted for the timing of the follow-up survey to control for the changes in risk perception in light of new information on risks being published (up to 14th June that marked the period of the strictest social distancing measures in the UK, 15th-30th June, and from 1st July due to very few people responding to the follow-up in the second half of July and in August).

\subsection{Additional factors perceived as increasing/decreasing the risk for severe Covid-19 symptoms}

Participants could provide additional free-text comments: "If you wish, please share what else you think can impact the risk of having more severe symptoms of COVID-19? Please include information on whether it increases or decreases the risk."

\subsection{Ethics and data management}

The study has been approved by UCL Research Ethics Committee at the UCL Division of Psychology and Language Sciences (CEHP/2020/ 579). Participants provided informed consent. The study data are collected and managed using REDCap (https://projectredcap.org/ (Harris et al., 2009)) hosted at UCL.

\subsection{Analyses}

The sample was weighted to Census and Annual Population Survey mid-year estimates for age, gender, ethnicity, country of living, education and household income (Office for National Statistics, 2020a). Data analysis was conducted in IBM SPSS 25 . We corrected for false discovery rate using the Benjamini-Hochberg procedure (Benjamini \& Hochberg, 1995).

For research question 1 , frequencies and percentages were calculated for the four answer options (lowers risk/no impact/increases risk/don't know) for each potential Covid-19 risk factor.

For research question 2, separate univariable analyses (chi-square) were conducted to assess the relationship between engaging in a health behaviour at the 1-month follow-up (smoking tobacco, e-cigarette use, nicotine replacement therapy use, alcohol drinking, regular physical activity, and eating unhealthy diet) with the risk perception for the corresponding behaviour. Multivariable logistic regression models were then conducted to assess whether engagement in concurrent health behaviours was independently associated with selecting the risk responses dichotomised into (each a separate model): (i) increase risk/all other, (ii) decrease risk/all other, and (iii) no impact/all other. This analysis was performed for answer options that were by at least $3 \%$ of the respondents allowing for the multivariable models to converge. Odds Ratios (ORs) and associated 95\% Confidence Intervals (CIs) were calculated. The multivariable logistic models were adjusted for all the variables listed in the measures.

For the third research question one researcher (initial) conducted content analysis (the answers provided by participants were brief, often containing only one or more factors separated by a comma) and another (initial) checked the coding and counts. The list of emerging themes and their tallies (unweighted) are presented.

\subsection{Sensitivity analyses}

First, we replicated all analyses using unweighted data. Secondly, we used $<£ 25.000$ vs $\geq £ 25.000$ as a cut-off value for the household income that was closer to the median household income in the UK of $£ 30.800$ (Office for National Statistics, 2020b). In the analysis of the correlates of risk perceptions for alcohol consumption we used a continuous alcohol weekly consumption score (frequency * units) and a categorical variable of frequency of heavy episodic drinking (HEDs; having at least 6 units of alcohol in a single session (Bradley et al., 2007), categorised into: no HEDs/HEDs less often than weekly/HEDs at least weekly).

\section{Results}

The analysis included $\mathrm{n}=2206$ (unweighted; $\mathrm{n}=1921$ weighted) UK adults, of whom $53.4 \%$ (weighted \%) were female, $71.1 \%$ were aged $36-69$, and $70.3 \%$ had post 16 years of age education (Table 1 ).

Table 2 reports on the risk perceptions of the individual factors. The 
Table 1

Sample characteristics (ns and \% are weighted).

\begin{tabular}{|c|c|}
\hline & $\begin{array}{l}\text { Included sample (complete } \\
\text { cases) }(\mathrm{n}=1921)\end{array}$ \\
\hline \multicolumn{2}{|l|}{$\begin{array}{l}\text { Characteristics assessed at baseline and } \\
\text { considered as time-invariant }\end{array}$} \\
\hline Female geneder vs all other, \%(n) ${ }^{\mathrm{a}}$ & $53.4(1026)$ \\
\hline White ethnicity vs all other, $\%(n)^{a}$ & $91.5(1757)$ \\
\hline Age $<35, \%(n)$ & $17.7(340)$ \\
\hline $36-69, \%(n)$ & $71.1(1366)$ \\
\hline $70+, \%(n)$ & $11.2(216)$ \\
\hline High school education or higher, \%(n) & $70.3(1352)$ \\
\hline Household income $\geq 50,000$ GBP $\%(n)$ & $17.9(344)$ \\
\hline$<50,000$ GBP, \%(n) & $75.0(1440)$ \\
\hline Prefer not to say, \%(n) & $7.1(137)$ \\
\hline House tenure: mortgage/own outright, \%(n) & 67.1 (1289) \\
\hline Has any health condition, $\%(n)^{a}$ & 45.7 (879) \\
\hline BMI: Normal or underweight (BMI $\leq 24.9$ ), $\%$ (n) & $39.4(756)$ \\
\hline Overweight $(25-29,9), \%(\mathrm{n})$ & $34.6(664)$ \\
\hline Obese $(\geq 30), \%(n)$ & $21.2(408)$ \\
\hline Data on BMI not available, \%(n) & $4.8(93)$ \\
\hline Living with vulnerable persons \%(n) & $16.2(311)$ \\
\hline Working as a key workerr \%(n) & $23.8(458)$ \\
\hline Characteristics assessed at 1-month follow-up & $(\mathrm{n}=1921)$ \\
\hline Employed (full-time or part-time), \%(n) & $48.6(935)$ \\
\hline $\begin{array}{l}\text { Covid-19 risk to one's health seen as minor/no } \\
\text { risk , \%(n) }\end{array}$ & 41.4 (795) \\
\hline Any current tobacco smoking, \%(n) & $18.6(358)$ \\
\hline Vaping currently, \%(n) & $14.7(282)$ \\
\hline $\begin{array}{l}\text { Alcohol:no alcohol consumed in past week, \% } \\
\text { (n) }\end{array}$ & $22.6(434)$ \\
\hline$\leq 14$ units of alcohol in the past week, $\%(n)$ & $53.6(1030)$ \\
\hline$>14$ units of alcohol in the past week, \%(n) & $23.8(457)$ \\
\hline $\begin{array}{l}\text { Fruit \& veg consumed a few times per day (vs } \\
\text { less often) }\end{array}$ & $56.2(1080)$ \\
\hline $\begin{array}{l}\text { Physical activity: meets the recommended } \\
\text { MVPA and MSA levels, \%(n) }\end{array}$ & $16.0(308)$ \\
\hline $\begin{array}{l}\text { Meets either MVPA or MSA recommended } \\
\text { levels, \%(n) }\end{array}$ & $36.4(700)$ \\
\hline Meets none, \%(n) & $47.5(913)$ \\
\hline
\end{tabular}

$\mathrm{GBP}=$ Great British Pounds, BMI = body mass index, $\mathrm{FT}=$ full time, $\mathrm{PT}=$ part time, MVPA = moderate to vigorous physical activity (aerobic), MSA $=$ muscle strength training.

a Including answer options 'prefer not to say'.

great majority of adults classified 'being 70 years old and older', having 'existing medical conditions', 'being from an ethnic minority', 'being a key worker', and 'being overweight' as increasing the risk for severe Covid-19 symptoms. Unhealthy behaviours or those that carry even minimal health risk (smoking, drinking alcohol, e-cigarette use) tended to be classified as increasing the risk for severe Covid-19 symptoms, while the behaviours that are healthy in general (e.g. regular physical activity) were rated as decreasing the risk or not having an impact on severe Covid-19 symptoms.

In all cases, engagement in a given health behaviour was associated with classification of risk for that behaviour (all $\mathrm{p}<0.001$, Table 3 ). Table 4 presents the fully adjusted ORs (95\% Cis) for the association between the engagement in a given health behaviour and classifying the corresponding health behaviour as increasing risk, decreasing risk or having no impact on severe Covid-19 symptoms, vs all others. Detailed findings from the fully adjusted models are presented in Supplementary material 2. In sixteen out of eighteen models tested, engagement in a given behaviour was significantly and independently associated with perceptions of that behaviour. The pattern of results showed evidence of optimism bias - the odds for classifying an unhealthy behaviour (e.g. smoking cigarettes) as decreasing the risk for severe Covid-19 symptoms were higher among those who were currently smoking tobacco (vs not who were not smoking tobacco). Conversely, those who reported eating fruit and vegetables a few times per day, versus those who did not, had higher odds to classify unhealthy diet as increasing the risk for severe Covid-19 symptoms and less likely to classify it as having no impact.
Table 2

Classification of factors in terms of risk or protective effect on severe Covid-19 symptoms among UK-based adults (organised in the order of agreement with increased risk). (All participants) - weighted $\mathrm{N}$ and $\%$.

\begin{tabular}{|c|c|c|c|c|}
\hline \multirow{3}{*}{$\begin{array}{l}\text { Factors identified as potential } \\
\text { risk factors for severe Covid-19 } \\
\text { symptoms }\end{array}$} & \multicolumn{4}{|c|}{$\begin{array}{l}\text { Classification of potential risk factors in relation } \\
\text { to severe Covid-19 symptoms }\end{array}$} \\
\hline & $\begin{array}{l}\text { Decrease } \\
\text { risk }\end{array}$ & $\begin{array}{l}\text { No } \\
\text { impact }\end{array}$ & $\begin{array}{l}\text { Increase } \\
\text { risk }\end{array}$ & $\begin{array}{l}\text { Don't } \\
\text { know }\end{array}$ \\
\hline & \multicolumn{4}{|c|}{$\%(\mathrm{~N}$ weighted) agreement } \\
\hline \multicolumn{5}{|l|}{$\begin{array}{l}\text { Socio-demographic and health } \\
\text { conditions }\end{array}$} \\
\hline Existing medical conditions & $0(1)$ & $0.5(9)$ & $\begin{array}{l}98.8 \\
(1898)\end{array}$ & $0.7(14)$ \\
\hline Being 70 years old and older & $0(0)$ & $1.6(30)$ & $\begin{array}{l}97.4 \\
(1872)\end{array}$ & $1.0(19)$ \\
\hline Being overweight & $0.05(10)$ & $4.8(92)$ & $\begin{array}{l}90.8 \\
(1744)\end{array}$ & $3.9(76)$ \\
\hline Being a key worker & $1.2(22)$ & $\begin{array}{l}6.1 \\
(117)\end{array}$ & $\begin{array}{l}89.7 \\
(1723)\end{array}$ & 3.1 (59) \\
\hline Being from an ethnic minority & $0.1(2)$ & $\begin{array}{l}5.6 \\
(108)\end{array}$ & $\begin{array}{l}88.9 \\
(1707)\end{array}$ & $\begin{array}{l}5.4 \\
(104)\end{array}$ \\
\hline Poor housing & $2.1(41)$ & $\begin{array}{l}17.2 \\
(331)\end{array}$ & $\begin{array}{l}73.6 \\
(1414)\end{array}$ & $\begin{array}{l}7.1 \\
(136)\end{array}$ \\
\hline Lower income & $2.4(45)$ & $\begin{array}{l}23.8 \\
(458)\end{array}$ & $\begin{array}{l}65.5 \\
(1258)\end{array}$ & $\begin{array}{l}8.4 \\
(161)\end{array}$ \\
\hline Vitamin D deficiency & $4.2(81)$ & $\begin{array}{l}16.2 \\
(312)\end{array}$ & $\begin{array}{l}60.9 \\
(1170)\end{array}$ & $\begin{array}{l}18.7 \\
(359)\end{array}$ \\
\hline \multicolumn{5}{|l|}{ Health behaviours } \\
\hline Smoking cigarettes & $6.0(115)$ & $\begin{array}{l}12.5 \\
(240)\end{array}$ & $\begin{array}{l}74.4 \\
(1430)\end{array}$ & $\begin{array}{l}7.1 \\
(136)\end{array}$ \\
\hline Eating unhealthy foods & $1.5(30)$ & $\begin{array}{l}23.4 \\
(450)\end{array}$ & $\begin{array}{l}64.2 \\
(1234)\end{array}$ & $\begin{array}{l}10.8 \\
(207)\end{array}$ \\
\hline Using e-cigarettes (vaping) & $3.4(65)$ & $\begin{array}{l}27.0 \\
(518)\end{array}$ & $\begin{array}{l}49.3 \\
(948)\end{array}$ & $\begin{array}{l}20.3 \\
(390)\end{array}$ \\
\hline Drinking alcohol & $2.4(46)$ & $\begin{array}{l}41.0 \\
(789)\end{array}$ & $\begin{array}{l}39.2 \\
(753)\end{array}$ & $\begin{array}{l}17.4 \\
(334)\end{array}$ \\
\hline $\begin{array}{l}\text { Using nicotine replacement } \\
\text { therapy (e.g. nicotine gum, } \\
\text { patch) }\end{array}$ & $10.7(206)$ & $\begin{array}{l}46.7 \\
(897)\end{array}$ & $\begin{array}{l}13.1 \\
(252)\end{array}$ & $\begin{array}{l}29.5 \\
(567)\end{array}$ \\
\hline Regular physical activity & $\begin{array}{l}64.9 \\
(1347)\end{array}$ & $\begin{array}{l}27.6 \\
(531)\end{array}$ & $2.2(43)$ & $\begin{array}{l}5.3 \\
(101)\end{array}$ \\
\hline Spending time in the sun & $49.8(958)$ & $\begin{array}{l}33.6 \\
(646)\end{array}$ & $1.7(33)$ & $\begin{array}{l}14.8 \\
(285)\end{array}$ \\
\hline
\end{tabular}

The classification of individual factors as increasing or decreasing the risk for severe Covid-19 symptoms was either not at all or only weakly associated with health behaviours that were different to the target factor in fully adjusted models (Supplementary material 1). For example, current tobacco smoking behaviour was not associated with risk perception of alcohol consumption, and vice-versa.

The conclusions did not change in the sensitivity analyses using unweighted data (Supplementary material 2; with the exception of three models (one for the NRT use and two for eating unhealthy foods) where the correlates did not meet the significance levels, albeit the ORs were very similar). The continuous variable of weekly alcohol consumption was also non-significantly associated with risk perceptions (Supplementary material 3).

\subsection{Other risk factors}

A sub-sample of 488 participants $(n=358(73.4 \%)$ were women, aged $\mathrm{M}=51.9, \mathrm{SD}=14.4$, unweighted) provided free-text comments regarding factors they perceived to be related to Covid-19. The details are presented in the Supplementary material 4 . While some of the listed factors included those already assessed by the HEBECO survey, the additional potential risk factors reported were: not following guidelines for social distancing or hygiene* $(n=98)$, gender* $(n=42)$, poor mental health or stress that could lower immunity* $(n=36)$, the degree of virus

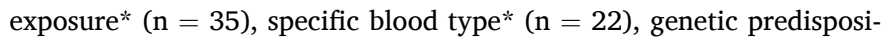
tion* $(n=13)$, certain medications, e.g. for blood pressure* $(n=4)$, lack of sleep* $(n=4)$, drug use* $(n=2)$, access to healthcare* $(n=2)$, air 
Table 3

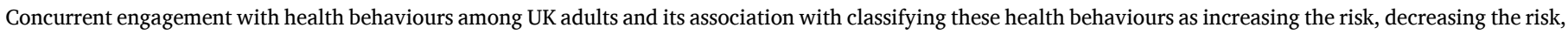
and having no impact for severe Covid-19 symptoms (results from chi-square).

\begin{tabular}{|c|c|c|c|c|c|c|}
\hline \multirow{3}{*}{$\begin{array}{l}\text { Potential risk factors for severe Covid-19 } \\
\text { assessed by UK adults }^{\mathrm{a}}\end{array}$} & \multirow{3}{*}{$\begin{array}{l}\text { Relevant health behaviour concurrent to } \\
\text { assessment of risks }{ }^{\mathrm{b}}\end{array}$} & \multicolumn{5}{|c|}{ Classification of risk factors by UK adults ${ }^{c}$} \\
\hline & & $\begin{array}{l}\text { Decrease risk vs all } \\
\text { other }\end{array}$ & $\begin{array}{l}\text { No impact vs all } \\
\text { other }\end{array}$ & $\begin{array}{l}\text { Increase risk vs all } \\
\text { other }\end{array}$ & \multirow[t]{2}{*}{$\begin{array}{l}\text { Don't } \\
\text { know }\end{array}$} & \multirow[t]{2}{*}{$\mathrm{p}^{\mathrm{d}}$} \\
\hline & & \multicolumn{3}{|l|}{$\%$ (weighted n) } & & \\
\hline \multirow[t]{2}{*}{ Smoking cigarettes } & Tobacco smoking & $10.1(36)$ & $22.6(81)$ & $57.8(207)$ & $9.5(34)$ & $<0.001$ \\
\hline & Non-use & $5.1(79)$ & $10.2(159)$ & $78.2(1223)$ & $6.6(103)$ & \\
\hline \multirow[t]{2}{*}{ Using e-cigarettes (vaping) } & E-cigarette use & $11.7(33)$ & $50.4(142)$ & $20.2(57)$ & $17.7(50)$ & $<0.001$ \\
\hline & Non-use & $2.0(32)$ & $23.0(377)$ & $54.3(891)$ & $\begin{array}{l}20.7 \\
(340)\end{array}$ & \\
\hline \multirow[t]{4}{*}{ Using nicotine replacement therapy ${ }^{\mathrm{b}}$} & Tobacco smoking & $19.6(70)$ & $49.0(175)$ & $8.7(31)$ & $22.7(81)$ & $<0.001$ \\
\hline & Non-use & $8.7(136)$ & $46.1(721)$ & $14.1(221)$ & $\begin{array}{l}31.0 \\
(485)\end{array}$ & \\
\hline & E-cigarette use & $17.7(50)$ & $60.8(172)$ & $5.3(15)$ & $16.3(46)$ & $<0.001$ \\
\hline & Non-use & $9.6(157)$ & $44.2(725)$ & $14.5(237)$ & $\begin{array}{l}31.7 \\
(520)\end{array}$ & \\
\hline \multirow[t]{3}{*}{ Drinking alcohol } & $>14$ alcohol units/week in the past month & $4.6(21)$ & 49.7 (227) & $33.0(151)$ & $12.7(58)$ & $<0.001$ \\
\hline & $\begin{array}{l}\leq 14 \text { alcohol units/week in the past } \\
\text { month }\end{array}$ & $1.3(13)$ & 40.7 (419) & $39.8(410)$ & $\begin{array}{l}18.3 \\
(188)\end{array}$ & \\
\hline & 0 alcohol units/week in the past month & $2.5(11)$ & $32.9(143)$ & $44.2(192)$ & $20.3(88)$ & \\
\hline \multirow[t]{3}{*}{ Regular physical activity } & Meets no requirements (ref) & $55.8(509)$ & $34.5(315)$ & $2.6(24)$ & $7.1(65)$ & $<0.001$ \\
\hline & Meets MSA or MVPA & $71.1(498)$ & 22.7 (159) & $2.0(14)$ & $4.1(29)$ & \\
\hline & Meets MSA and MVPA & $77.7(240)$ & $18.4(57)$ & $1.6(5)$ & $2.3(7)$ & \\
\hline \multirow[t]{2}{*}{ Eating unhealthy foods ${ }^{c}$} & Fruit \& veg a few times/day & $1.5(16)$ & $19.1(206)$ & $69.4(750)$ & $\begin{array}{l}10.8 \\
(108)\end{array}$ & $<0.001$ \\
\hline & Not & $1.5(13)$ & $29.1(245)$ & $57.6(484)$ & 11.8 (99) & \\
\hline
\end{tabular}

MSA: muscle-strengthening activity, MVPA: moderate and vigorous physical activity. 1: The behaviour of using nicotine replacement therapy was not assessed as part of the HEBECO survey at the 1 month follow-up, and for the present analysis we used the behaviours of tobacco smoking and electronic cigarettes use as proxies as both tobacco products and e-cigarettes commonly include nicotine. 2: We used the behaviour of 'eating fruit and vegetables' as a proxy of unhealthy diet.

${ }^{\text {a }}$ List of health behaviours that UK adults were provided to classify as potential risk factors for severe Covid-19 symptoms.

b UK adults were classified as either engaging or not in that health behaviour.

${ }^{\mathrm{c}}$ Classification of risk factors listed in column 1.

${ }^{\mathrm{d}} \mathrm{p}$-Value scores from chi-square tests.

Table 4

Concurrent engagement with health behaviours as an independent predictor of classifying these health behaviours as increasing the risk, decreasing the risk, and having no impact for severe Covid-19 symptoms (each cells presents results from a separate unadjusted and fully adjusted logistic regression models).

\begin{tabular}{|c|c|c|c|c|}
\hline \multirow[t]{2}{*}{$\begin{array}{l}\text { Potential risk factors for severe } \\
\text { Covid-19 }\end{array}$} & \multirow[t]{2}{*}{$\begin{array}{l}\text { Correlates: Relevant health behaviour concurrent to } \\
\text { assessment of risks }\end{array}$} & $\begin{array}{l}\text { Decrease risk vs all } \\
\text { other }\end{array}$ & $\begin{array}{l}\text { No impact vs all } \\
\text { other }\end{array}$ & $\begin{array}{l}\text { Increase risk vs all } \\
\text { other }\end{array}$ \\
\hline & & \multicolumn{3}{|l|}{$\mathrm{aOR}^{1}, 95 \% \mathrm{CI}$} \\
\hline Smoking cigarettes & Tobacco smoking (vs not) & $2.26(1.39-3.37)^{*}$ & $1.98(1.42-2.76)^{*}$ & $0.43(0.32 .-56)^{*}$ \\
\hline Using e-cigarettes (vaping) & E-cigarette use (vs not) & $5.80(3.25-10.34)^{*}$ & $2.63(1.96-3.50)^{*}$ & $0.25(0.18-0.35)^{*}$ \\
\hline \multirow[t]{2}{*}{ Using nicotine replacement therapy ${ }^{2}$} & Tobacco smoking (vs not) & $2.64(1.85-3.77)^{*}$ & $0.95(0.73-1.22)$ & $0.63(0.41-0.97)$ \\
\hline & E-cigarette use (vs not) & $1.74(1.18-2.56)^{* \mathrm{u}}$ & $1.80(1.36-2.38) *$ & $0.34(0.20-0.60)^{*}$ \\
\hline \multirow[t]{3}{*}{ Drinking alcohol } & 0 alcohol units/week & $-{ }^{\mathrm{a}}$ & 1.0 & 1.0 \\
\hline & $\leq 14$ alcohol units/week & $\mathrm{-a}^{\mathrm{a}}$ & $1.58(1.23-2.03)$ & $0.72(0.57-0.92)$ \\
\hline & $>14$ alcohol units/week & $\mathrm{a}^{\mathrm{a}}$ & $1.75(1.31-2.33)$ & $0.70(0.53-0.93)$ \\
\hline \multirow[t]{3}{*}{ Regular physical activity } & Meets no requirements (ref) & 1.0 & 1.0 & $-^{\mathrm{a}}$ \\
\hline & Meets MSA or MVPA & $1.72(1.38-2.16)^{*}$ & $0.62(0.49-0.79)^{*}$ & $\mathrm{a}^{\mathrm{a}}$ \\
\hline & Meets MSA and MVPA & $2.42(1.75-3.34)^{*}$ & $0.50(0.35-0.70)^{*}$ & $\mathrm{-a}^{\mathrm{a}}$ \\
\hline Eating unhealthy foods ${ }^{3}$ & Fruit \& veg a few times/day (vs not) & $\mathrm{s}^{\mathrm{a}}$ & $0.71(0.56-0.90)^{* u}$ & $1.37(1.12-1.69)^{* \mathrm{u}}$ \\
\hline
\end{tabular}

MSA: muscle-strengthening activity, MVPA: moderate and vigorous physical activity; * (and bold) marks results that were significant following BH correction (pvalue $<0.015$ ); '- a' signifies that this model was not run due to low prevalence of endorsement of this answer option; $u=$ not significant in unweighted analysis.

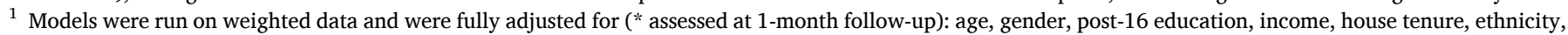

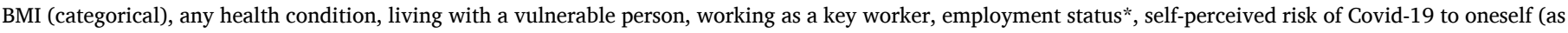

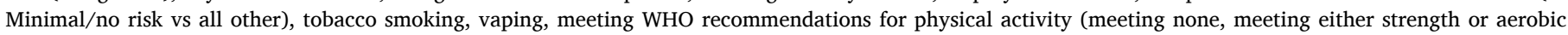
activity, meeting both), diet (binary: eating fruit and veg a few times per day (vs not)); time of follow-up (3 levels).

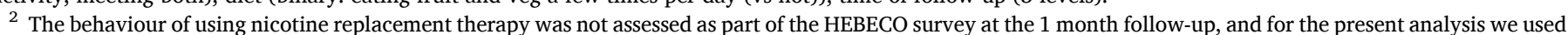
the behaviours of tobacco smoking and electronic cigarettes use as proxies as both tobacco products and e-cigarettes commonly include nicotine.

3 We used the behaviour of 'eating fruit and vegetables' as a proxy of unhealthy diet.

pollution* $(n=1)$.

\section{Discussion}

\subsection{Overview of findings}

To our knowledge, this is the first study to investigate the risk perceptions regarding health behaviours alongside other factors for severe 
Covid-19 symptoms among UK-based adults. The findings can inform future public health communication, programmes and research. Firstly, UK adults were well aware of the factors that had been repeatedly presented as risk factors for severe Covid-19 by public health authorities in the UK at the time of data collection on risk perceptions (i.e. June-August 2020). Secondly, risk perceptions aligned with general classification of behaviours and conditions into healthy and unhealthy. Healthy behaviours (e.g. regular physical activity) tended to be classified as decreasing the risk for severe Covid-19 symptoms. Conversely, unhealthy behaviours (e.g. eating unhealthy foods, smoking cigarettes) were classified as increasing the risk.

Furthermore, one's own health behaviour was strongly predictive of risk classification for that behaviour, showing optimism bias (Bottemanne et al., 2020; Sharot, 2011). Thus, for example, current tobacco smokers, e-cigarette users and alcohol drinkers were less likely to consider their own behaviours of smoking, vaping and drinking, respectively, as factors that increased the risk for severe Covid-19 symptoms than those who did not engage in these behaviours. This being a cross-sectional study, the direction of effect cannot be determined. For example, an alternative explanation of the present findings could be that at last in some circumstances participants' prior and persisting risk perceptions, knowledge or information seeking about their past behaviours, have already led them to change their behaviour before data collection. For example, as a result of their prior risk perceptions or beliefs some people might have quit smoking or increased physical activity in order to lower their perceived risk of suffering from severe Covid-19 symptoms. However, this is unlikely to explain all the present findings that are consistently aligned with optimism bias. We can expect this self-protective bias to occur if adults wanted to reduce unpleasant cognitive dissonance arising from beliefs that their current behaviour may be increasing their risk for new and severe health conditions and outcomes.

The greatest uncertainty regarding the impact of health conditions and behaviours on the risk of severe Covid-19 symptoms existed for the use of NRT, drinking alcohol, and vitamin D deficiency. These findings are reflecting the current scientific uncertainty regarding the relationship between these behaviours and Covid-19 symptom severity. Interestingly, only a small minority of adults classified smoking cigarettes $(6.0 \%)$ and vaping (3.4\%) as decreasing the risk for severe Covid-19 symptoms, suggesting that the hypotheses pertaining to potentially protective effect of nicotine use on infection or Covid-19 (Farsalinos et al., 2020a; Farsalinos et al., 2020b) have not been widely noticed by UK adults, at least in the summer of 2020 .

The open-ended comments provided by a sub-sample of the respondents tended to focus on poor physical health, but also poor mental health and low adherence to social distancing measures as risk factors for severe Covid-19.

\subsection{Implications}

The present findings confirm the relevance of investigating optimism bias during periods where behaviour change can be key to public health outcomes, such as during the pandemics. The findings also have several practical implications, including for health policy and campaigns. On the one hand, they suggest that risk perceptions for severe Covid-19 symptoms in the UK reflected the contemporary reports on risks in the governmental and public health media in the UK (e.g. for risk factors such as age, having obesity), suggesting that the communication had been effective. It will be important to maintain appropriate and effective channels of communication as the pandemic progresses and knowledge on the risks and protective effects of Covid-19 is updated. On the other hand, in the context of mixed message communication or in the absence of clear messaging regarding other risk factors there may be a tendency to interpret one's own behaviour as favourable during the pandemic. In line with several theories and models of behaviours, such as COM-B (Michie et al., 2011), PMT (Rogers \& Protection, 1975) or the EPPM
(Witte, 1992), optimism bias concerning unhealthy behaviours (e.g. smoking, alcohol drinking) could lower motivation for positive lifestyle changes and thus could exacerbate substantial inequalities in healthprotective behaviours and their outcomes.

As a consequence, health promotion campaigns during the current and future pandemics should consider the possibility that certain risk perceptions and optimism bias may form additional barriers to positive health behaviour change and make one less responsive to interventions that refer to the risk of COVID as a motivating factor. Such campaigns and health promotion interventions should address possible cognitive biases, for example by providing personalised or targeted messaging. Some experimental studies showed that optimism bias may be minimised in some circumstances, for example when presenting information about other people's behaviours (Cutello et al., 2021) or providing insights into the actual risk levels (Dolinski et al., 2021), but more research on this is needed.

Furthermore, as this was an observational and cross-sectional study, a number of future research directions should be explored. Firstly, it will be important to use longitudinal designs to explore whether optimism bias is indeed affecting motivation to change behaviour (e.g. motivation to quit among smokers) and the actual behaviour change, as proposed by the different psychological theories. It would also be informative to assess the stability of risk perceptions and optimism bias over the course of the pandemic. Secondly, experimental designs could be employed to evaluate interventions addressing optimism bias. Other investigations could assess whether holding certain risk perceptions about one's own health behaviours with regards to Covid-19 is associated with adherence to social distancing measures or other protective behaviours, such as taking up vaccinations for Covid-19 or use of face coverings. Finally, there are a number of other factors that could influence risk perceptions during the pandemic, including psychological factors, such as negative affect or anxiety (Zhong et al., 2021), as well as the levels of knowledge and information sources one accesses (Motta-Zanin et al., 2020). These factors were not assessed in the present study and should be considered in future research.

\subsection{Strengths and limitations}

The study benefited from a large sample size, as well as from including a wide range of covariates, validated measures and timely assessment during an ongoing pandemic, increasing robustness and reducing the risk of recall bias and confounding. It also suffers from some limitations. This being a cross-sectional analysis we cannot determine the direction of causality and it is possible that the respondents have changed their behaviour in accordance with their beliefs, or vice-versa. Additionally, although the sample at baseline was weighted for the UK Census data, due to attrition it became less representative at 1-month follow-up and the sample with complete data included in the current analyses comprised a more educated population with over representation of female gender and white ethnicity. Further research is required to examine whether our findings hold among ethnic minority and socially disadvantaged groups.

Additionally, participants were asked to select only from four answer options for each factor listed (i.e. increases risk, lowers risk, no impact, and don't know) and therefore we could not assess the strength of belief, which can also help explain the ceiling effect reached for endorsement of the common risk factors. However, previous studies on beliefs in risk factors that used 5-point scale have commonly dichotomised the answers for the analysis (e.g. 'increases risk' vs all other) (Shahab et al., 2018). In two cases the behavioural correlated of the risk factors assessed was not perfectly matched but we believe they were sufficient proxies, i.e. we used the self-reported low consumption of fruit and vegetable as a proxy for consuming unhealthy foods, and we assessed risk perceptions towards NRT among tobacco and ex-cigarette use (as the latter two types of products commonly include nicotine that is also in NRT). Finally, severe Covid-19 symptoms were not defined as part of the 
question in the survey and could have been interpreted by participants in different ways. The question did not aim to assess factual knowledge of the potential risk factors and their association with the different possible severe Covid-19 outcomes (e.g. becoming infected, hospitalisation among those who are infected, death among those who are hospitalised), but rather to assess more subjective classification of risks. There could be individual differences in what people would classify as severe symptoms or not, which is a limitation. To account for potential biases that this approach could introduce the analyses were adjusted for many other factors and confounders (e.g. existence of any health condition).

\section{Conclusions}

During the early stages of the Covid-19 pandemic, beliefs in risks for severe Covid-19 symptoms were in line with general classifications of health conditions and behaviours as healthy or unhealthy, and were significantly inversely associated with adults' own health behaviours. Therefore, while some risk perceptions indicated effective communication by the UK media, there was evidence of optimism bias including among those with unhealthy behaviours (e.g. smoking, alcohol drinking), which could lower motivation for positive lifestyle changes and thus exacerbate health inequalities. These findings could have implications for the design and implementation of health policy and programmes.

\section{Funding}

This project is partially funded by an ongoing Cancer Research UK Programme Grant to UCL Tobacco and Alcohol Research Group [grant number C1417/A22962] and by SPECTRUM a UK Prevention Research Partnership Consortium [grant number MR/S037519/1].

\section{CRediT authorship contribution statement}

AH and LS co-lead on the HEBECO project. AH conceptualised the study, analysed the quantitative data, and prepared the first version of the manuscript. JB, DK, CG and TC contributed to the survey design. JB, CG, SJ, DK, MZ, and LS contributed to the study design. DK conducted the thematic analysis. All authors contributed to the preparation of, and approve, the final version of the manuscript. The views expressed in this article are those of the authors and are not necessarily those of Public Health England or the Department of Health and Social Care.

\section{Declaration of competing interest}

JB has received unrestricted research funding to study smoking cessation from companies who manufacture smoking cessation medications (Pfizer and J\&J). All other author(s) declared that there were no conflicts of interest with respect to the authorship or the publication of this article. All authors declare no financial links with tobacco companies or e-cigarette manufacturers or their representatives.

\section{Acknowledgements}

We are grateful to all participants who have been supporting our research. We would like to thank Public Health England, and particularly members of the Behavioural Insights at Public Health England for providing feedback on the survey wording. We would like to thank Public Health England, Cancer Research UK, local authorities, Mayors' offices, as well as charities and other organisations in the UK, including the Asthma UK and British Lung Foundation Partnership, for supporting our recruitment campaign. We would like to also acknowledge Verena Schneider's assistance with preparation of variables for analyses and Rhea Kohli's assistance with the preparation of supplementary materials.

\section{Appendix A. Supplementary data}

Supplementary data to this article can be found online at https://doi. org/10.1016/j.actpsy.2021.103458.

\section{References}

Abdelrahman, M. (2020). Personality traits, risk perception, and protective behaviors of Arab residents of Qatar during the COVID-19 pandemic. International Journal of Mental Health and Addiction, 1-12.

Aghababaeian, H., Hamdanieh, L., \& Ostadtaghizadeh, A. (2020). Alcohol intake in an attempt to fight COVID-19: A medical myth in Iran. Alcohol, 88, 29-32.

ASH. (2020). COVID-19 drives 'astonishing' quit rate among young smokers: Experts ask if trend will survive loosening lockdown. Available from: Retrieved from https://ash. org.uk/media-and-news/press-releases-media-and-news/covidyoungsmokers/.

Aveyard, P., Lindson, N., Gao, M., Hartmann-Boyce, J., Smith, M., \& Young, D. (2020). Associations between COVID-19 infection, tobacco smoking and nicotine use, common respiratory conditions and inhaled corticosteroids: A prospective QResearch-Case Mix Programme data linkage study January-May 2020. MedRxiv.

Benjamini, Y., \& Hochberg, Y. (1995). Controlling the false discovery rate: A practical and powerful approach to multiple testing. Journal of the Royal Statistical Society: Series B (Methodological), 57, 289-300.

Bennie, J. A., De Cocker, K., Teychenne, M. J., Brown, W. J., \& Biddle, S. J. H. (2019). The epidemiology of aerobic physical activity and muscle-strengthening activity guideline adherence among 383,928 U.S. adults. International Journal of Behavioral Nutrition and Physical Activity, 16, 34.

Bottemanne, H., Morlaas, O., Fossati, P., \& Schmidt, L. (2020). Does the coronavirus epidemic take advantage of human optimism bias? Frontiers in Psychology, 11, 2001.

Bradley, K. A., DeBenedetti, A. F., Volk, R. J., Williams, E. C., Frank, D., \& Kivlahan, D. R. (2007). AUDIT-C as a brief screen for alcohol misuse in primary care. Alcoholism, Clinical and Experimental Research, 31, 1208-1217.

Branstrom, R., Kristjansson, S., \& Ullen, H. (2006). Risk perception, optimistic bias, and readiness to change sun related behaviour. European Journal of Public Health, 16, 492-497.

Brewer, N. T., Chapman, G. B., Gibbons, F. X., Gerrard, M., McCaul, K. D., \& Weinstein, N. D. (2007). Meta-analysis of the relationship between risk perception and health behavior: The example of vaccination. Health Psychology, 26, 136-145.

Brust, M., Gebhardt, W. A., Numans, M. E., \& Kiefte-de Jong, J. C. (2021). The COVID-19 crisis as a teachable moment for lifestyle change in dutch cardiovascular disease patients. Frontiers in Psychology, 12, Article 678513.

Butler, M. J., \& Barrientos, R. M. (2020). The impact of nutrition on COVID-19 susceptibility and long-term consequences. Brain, Behavior, and Immunity, 87, 53-54.

CDC. (2020). People with certain medical conditions. Available from: Retrieved from: https://www.cdc.gov/coronavirus/2019-ncov/need-extra-precautions/people-withmedical-conditions.html?CDC_AA_refVal=https\%3A\%2F\%2Fwww.cdc.gov\%2Fcoro navirus\%2F2019-ncov\%2Fneed-extra-precautions\%2Fgroups-at-higher-risk.html.

Changeux, J.-P., Amoura, Z., Rey, F., \& Miyara, M. (2020). A nicotinic hypothesis for Covid-19 with preventive and therapeutic implications. Qeios. https://www.qeios. $\mathrm{com} / \mathrm{read} / \mathrm{FXGQSB}$.

Chapin, J. (2010). It Won't happen to me: The role of optimistic bias in african american Teens' risky sexual practices. Howard Journal of Communications, 12, 49-59.

Critchlow, N., Newberry Le Vay, J., MacKintosh, A. M., Hooper, L., Thomas, C., Vohra, J., Correction, \& Critchlow, N. (2020). Adolescents' reactions to adverts for fast-food and confectionery brands that are high in fat, salt, and/or sugar (HFSS), and possible implications for future research and regulation: Findings from a cross-sectional survey of 11-19 year olds in the United Kingdom. International Journal of Environmental Research and Public Health, 17, 1689. Int J Environ Res Public Health, $2021 ; 18$.

Cutello, C. A., Walsh, C., Hanoch, Y., \& Hellier, E. (2021). Reducing optimism bias in the driver's seat: Comparing two interventions. Transportation Research Part F: Traffic Psychology and Behaviour, 78, 207-217.

Dalton, N. (2020). Coronavirus: France limits nicotine patch sales after researchers say product may protect against disease. Available from: Retrieved from: https://www. independent.co.uk/news/world/europe/coronavirus-france-nicotine-patch-gum-re search-covid-19-a9484696.html.

Dillard, A. J., McCaul, K. D., \& Klein, W. M. (2006). Unrealistic optimism in smokers: Implications for smoking myth endorsement and self-protective motivation. Journal of Health Communication, 11(Suppl. 1), 93-102.

Dolinski, D., Kulesza, W., Muniak, P., Dolinska, B., Wegrzyn, R., \& Izydorczak, K. (2021). Media intervention program for reducing unrealistic optimism bias: The link between unrealistic optimism, well-being, and health. Applied Psychology. Health and Well-Being, 1-20. https://doi.org/10.1111/aphw.12316

Dryhurst, S., Schneider, C. R., Kerr, J., Freeman, A. L. J., Recchia, G., van der Bles, A. M., et al. (2020). Risk perceptions of COVID-19 around the world. Journal of Risk Research, 23, 994-1006.

Farsalinos, K., Barbouni, A., \& Niaura, R. (2020). Systematic review of the prevalence of current smoking among hospitalized COVID-19 patients in China: Could nicotine be a therapeutic option? Internal and Emergency Medicine, 15, 845-852.

Farsalinos, K., Niaura, R., Le Houezec, J., Barbouni, A., Tsatsakis, A., Kouretas, D., et al. (2020). Editorial: Nicotine and SARS-CoV-2: COVID-19 may be a disease of the nicotinic cholinergic system. Toxicology Reports, 7, 658-663.

Ferrer, R., \& Klein, W. M. (2015). Risk perceptions and health behavior. Current Opinion in Psychology, 5, 85-89. 
Fidler, J. A., Shahab, L., West, R., Jarvis, M. J., McEwen, A., Stapleton, J. A., et al. (2011). 'The smoking toolkit study': A national study of smoking and smoking cessation in England. BMC Public Health, 11, 479.

Gawronski, B. (2012). Back to the future of dissonance theory: Cognitive consistency as a Core motive. Social Cognition, 30, 652-668.

Grant, W. B., Lahore, H., McDonnell, S. L., Baggerly, C. A., French, C. B., Aliano, J. L., et al. (2020). Evidence that vitamin D supplementation could reduce risk of influenza and COVID-19 infections and deaths. Nutrients, 12.

Harris, P. A., Taylor, R., Thielke, R., Payne, J., Gonzalez, N., \& Conde, J. G. (2009). Research electronic data capture (REDCap)-a metadata-driven methodology and workflow process for providing translational research informatics support. Journal of Biomedical Informatics, 42, 377-381.

Hartmann-Boyce, J., \& Lindson, N. (2020). The role of nicotine in COVID-19 infection. Available from: Accessed 01 Sept 2020 from: https://www.cebm.net/covid-19/ni cotine-replacement-therapy/\#: : :text=Nicotine $\% 20$ and $\% 20$ cigarette $\% 20$ smoke $\%$ 20decrease, inhibit $\% 20$ hyperinflammation $\% 20$ and $\% 20$ platelet $\% 20$ reactivity.

Ioannou, G. N., Locke, E., Green, P., Berry, K., O'Hare, A. M., Shah, J. A., et al. (2020). Risk factors for hospitalization, mechanical ventilation, or death among 10131 US veterans with SARS-CoV-2 infection. JAMA Network Open, 3, Article e2022310.

Katapodi, M. C., Lee, K. A., Facione, N. C., \& Dodd, M. J. (2004). Predictors of perceived breast cancer risk and the relation between perceived risk and breast cancer screening: A meta-analytic review. Preventive Medicine, 38, 388-402.

Masiero, M., Riva, S., Oliveri, S., Fioretti, C., \& Pravettoni, G. (2018). Optimistic bias in young adults for cancer, cardiovascular and respiratory diseases: A pilot study on smokers and drinkers. Journal of Health Psychology, 23, 645-656.

Michie, S., van Stralen, M. M., \& West, R. (2011). The behaviour change wheel: A new method for characterising and designing behaviour change interventions. Implementation Science, 6, 42.

Miyara, M., Tubach, F., Pourcher, V., Morelot-Panzini, C., Pernet, J., Haroche, J., et al. (2020). Low incidence of daily active tobacco smoking in patients with symptomatic COVID-19. Qeios. https://www.qeios.com/read/WPP19W.3.

Motta-Zanin, G., Gentile, E., Parisi, A., \& Spasiano, D. (2020). A preliminary evaluation of the public risk perception related to the COVID-19 health emergency in Italy. International Journal of Environmental Research and Public Health, 17.

NHS. (2020). Who's at higher risk from coronavirus.

Nickerson, R. S. (1998). Confirmation bias: A ubiquitous phenomenon in many guises. Review of General Psychology, 2, 175-220.

Office for National Statistics. (2020). Estimates of the population for the UK, England and Wales, Scotland and Northern Ireland. Available from: Retrieved from: https ://www.ons.gov.uk/peoplepopulationandcommunity/populationandmigration/pop ulationestimates/datasets/populationestimatesforukenglandandwalesscotlandandn orthernireland.

Office for National Statistics. (2020). Average household income, UK: Financial year ending 2020 (provisional). Available from: Accessed on 30th Nov 2020 from: http s://www.ons.gov.uk/peoplepopulationandcommunity/personalandhouseholdfinanc es/incomeandwealth/bulletins/householddisposableincomeandinequality/financ ialyearending2020provisional\#: : text=More\%20information\%20about $\% 20$ this\% 20process,30\%2C100)\%20shown\%20in\%20Figure $\% 201$.

Presson, P. K., \& Benassi, V. A. (1996). Illusion of control: A meta-analytic review. Journal of Social Behavior and Personality, 11.

Public Health England. (2021). Campaign launched to help public get healthy this summer [cited 26 July 2021; Available from: https://www.gov.uk/government/ne ws/campaign-launched-to-help-public-get-healthy-this-summer.
Rhodes, J. M., Subramanian, S., Laird, E., \& Kenny, R. A. (2020). Editorial: Low population mortality from COVID-19 in countries south of latitude 35 degrees north supports vitamin D as a factor determining severity. Alimentary Pharmacology \& Therapeutics, 51, 1434-1437.

Rogers, R. W., \& Protection, A. (1975). Motivation theory of fear appeals and attitude Change1. The Journal of Psychology, 91, 93-114.

Sallis, J. F., Adlakha, D., Oyeyemi, A., \& Salvo, D. (2020). An international physical activity and public health research agenda to inform coronavirus disease-2019 policies and practices. Journal of Sport and Health Science, 9, 328-334.

Shahab, L., McGowan, J. A., Waller, J., \& Smith, S. G. (2018). Prevalence of beliefs about actual and mythical causes of cancer and their association with socio-demographic and health-related characteristics: Findings from a cross-sectional survey in England. European Journal of Cancer, 103, 308-316.

Sharot, T. (2011). The optimism bias. Current Biology, 21, Article R941-5.

Shokoohi, M., Nasiri, N., Sharifi, H., Baral, S., \& Stranges, S. (2020). A syndemic of COVID-19 and methanol poisoning in Iran: Time for Iran to consider alcohol use as a public health challenge? Alcohol, 87, 25-27.

Siegrist, M., Luchsinger, L., \& Bearth, A. (2021). The impact of trust and risk perception on the acceptance of measures to reduce COVID-19 cases. Risk Analysis, 41, 787-800.

Simons, D., Shahab, L., Brown, J., \& Perski, O. (2020). The association of smoking status with SARS-CoV-2 infection, hospitalisation and mortality from COVID-19: A living rapid evidence review with bayesian meta-analyses (version 9). Qeios. https://www. qeios.com/read/UJR2AW.11.

Tattan-Birch, H., Perski, O., Jackson, S., Shahab, L., West, R., \& Brown, J. (2020). COVID19, smoking, vaping and quitting: A representative population survey in England. Addiction, 116(5), 1186-1195.

The OpenSAFELY Collaborative, Williamson, E., Walker, A. J., Bhaskaran, K. J., Bacon, S., \& Bates, C. (2020). OpenSAFELY: Factors associated with Covid-19-related hospital death in the linked electronic health records of 17 million adult NHS patients. medRxiv.

UK Department of Health. (2016). UK Chief Medical Officers' Alcohol Guidelines Review.

Ward, H., Atchison, C. J., Whitaker, M., Ainslie, K. E. C., Elliott, J., \& Okell, L. C. (2020), Antibody prevalence for SARS-CoV-2 in England following first peak of the pandemic: REACT2 study in 100,000 adults. MedRxiv.

Weinstein, N. D. (1980). Unrealistic optimism about future life events. Journal of Personality and Social Psychology, 39, 806-820.

WHO. (2020). WHO Coronavirus Disease (COVID-19) dashboard. Available from: Accesed on 14th December 2020 from: https://covid19.who.int/.

Wilder, C. M., Miller, S. C., Tiffany, E., Winhusen, T., Winstanley, E. L., \& Stein, M. D. (2016). Risk factors for opioid overdose and awareness of overdose risk among veterans prescribed chronic opioids for addiction or pain. Journal of Addictive Diseases, 35, 42-51.

Wise, T., Zbozinek, T. D., Michelini, G., Hagan, C. C., \& Mobbs, D. (2020). Changes in risk perception and self-reported protective behaviour during the first week of the COVID-19 pandemic in the United States. Royal Society Open Science, 7, Article 200742.

Witte, K. (1992). Putting the fear back into fear appeals: The extended parallel process model. Communication Monographs, 59, 329-349.

Zhong, Y., Liu, W., Lee, T. Y., Zhao, H., \& Ji, J. (2021). Risk perception, knowledge, information sources and emotional states among COVID-19 patients in Wuhan China. Nursing Outlook, 69, 13-21. 